\title{
Testicular Fine Needle Aspiration Cytology versus Open Biopsy in the Evaluation of Azoospermic Men
}

\author{
Ala'a Al-Deen Al-Dabbagh', Basim Sh. Ahmed² \\ ${ }^{1}$ Department of Surgery, College of Medicine, Al-Mustansiriya University, Baghdad, Iraq \\ ${ }^{2}$ Department of Pathology, College of Medicine, Al-Mustansiriya University, Baghdad, Iraq \\ Email: alaaa1962@yahoo.co.uk
}

Received 16 July 2015; accepted 28 August 2015; published 31 August 2015

Copyright (C) 2015 by authors and Scientific Research Publishing Inc.

This work is licensed under the Creative Commons Attribution International License (CC BY). http://creativecommons.org/licenses/by/4.0/

(c) (i) Open Access

\section{Abstract}

Background: Male infertility is a common problem and needs a minimally invasive method to arrive at the appropriate diagnosis. Alternative to open testicular biopsy the fine needle aspiration cytology (FNAC) of the testis is being increasingly used as a minimally invasive method of evaluating testicular function. Aim: To determine the causes of azoospermia and evaluate the efficacy of FNAC as compared to open testicular biopsy in evaluating azoosparmic men by correlating diagnosis from testis FNAC with biopsy histology. Patients and Methods: We prospectively studied 67 consecutive infertile patients who referred to andrology department of Al-Yarmouk Teaching hospital, Baghdad, Iraq between (January 2010-January 2014). All patients were azoospermic. They underwent bilateral testicular fine needle aspiration for cytological evaluation as well as bilateral testicular biopsy for histopathological correlation. Results: The morphological diagnosis revealed normal spermatogenesis in 12 patients $(17.9 \%)$, hyposparmatogenesis in 4 (5.9\%), spermatogenic arrest in 39 (58.2\%), Sertoli cell only in 7 (10.4\%), and complete tubular hyalinization in 5 patients (7.4\%). Good correlation between the 2 methods was found in 120 (91.6\%) testes which was identical in the right and left testis. Discrepancies between cytology and histology were mainly the result of insufficient and scanty smears. Conclusion: Testicular FNAC is a simple and minimally invasive alternative method to open testicular biopsy in the investigation and assessment of patients with azoospermia.

\section{Keywords}

Azoospermia, Testis FNA, Biopsy, Cytology, Histology 


\section{Introduction}

Azoospermia, defined as the absence of spermatozoa in the ejaculate after assessment of centrifugated semen on at least 2 occasions, affects approximately $1 \%$ of the male population \& $10 \%$ of men who seek fertility evaluation [1].

The etiology of azoospermia may be attributed to 1) pre-testicular causes (e.g., endocrine abnormalities causing secondary testicular failure), 2) testicular causes (e.g., primary testicular failure due to intrinsic disorders of spermatogenesis within the testis, including maturation arrest, complete absence of germ cells or Sertoli cellonly syndrome), or 3) post testicular causes (e.g., ejaculatory dysfunction or ductal obstruction that prevent sperm transport) [2].

To distinguish between obstructive \& non-obstructive azoospermia testicular biopsy may be performed. Although surgical biopsy of the testis has generally been regarded as the gold standard in the evaluation of male infertility [3], testicular fine needle aspiration (FNA) is also considered as an alternative method that has gained increasing popularity as a simple, minimally invasive procedure that can help in assessing testicular function accurately [3]-[7]. Both methods give a clear assessment of spermatogenesis and allow a rational choice for the future management of the couple by reconstructive surgery, hormonal therapy, artificial donor insemination or adoption [8].

We had done this study to determine the causes of azoospermia and evaluate the efficacy of FNAC as compared to open testicular biopsy in evaluating azoospermic men by correlating diagnosis from testis FNAC with biopsy histology.

\section{Patients and Methods}

The study included 67 male patients with ages ranged from 20 to 35 years and infertility ranged from 1 to 20 years. They attended the andrology clinic at Al-Yarmouk Teaching Hospital, a tertiary hospital in Baghdad/Iraq with a total number of admissions including emergency admission of 216,000 patients per year, in the period between January 2010 and January 2014. History taking (including fertility, sexual, genitourinary, general, medical and drug history) and a complete physical examination were done for each patient with special emphasis on the genitalia (penis, testis size and consistency, epididymisconsistency, vasa differentia presence and consistency, spermatic cords and inguinal regions).

Laboratory testing including urinalysis and endocrine evaluation were performed on all patients, karyotyping to exclude chromosomal abnormalities. Scrotal ultrasound (U/S) and trans rectal ultrasound (TRUS), to evaluate the seminal vesicles and the ejaculatory ducts, were done as indicated.

Inclusion criteria were male patients with the presence of azoospermia and exclusion criteria were karyotype abnormalities and testicular volume less than $5 \mathrm{ml}$ (to prevent subsequent defect in androgen synthesis)

Patients were then subjected to fine needle aspiration of the testes for cytological evaluation. A specimen for histopathological correlation was obtained from the same patients by open testicular biopsy. The work was conducted in compliance with Institutional Review Board/Human Subjects Research Committee requirements.

The procedures of the FNAC of the testes were done in the surgical outpatient. With the patient in the supine position, the scrotal skin was prepared with $5 \%$ betadine solution. $5 \mathrm{ml}$ of $1 \%$ xylocaine was injected into the spermatic cord bilaterally. The testis was positioned with the epididymis directed posteriorly. The scrotal skin was stretched over the skin by wrapping the scrotal skin behind the testis with a sponge. The planned aspiration sites were marked on the scrotal skin overlying the testis. Aspiration was done with a 23 gauge fine needle attached to a $10 \mathrm{ml}$ disposable syringe and using the established suction-cutting technique (in and out movements varying from 5 - $8 \mathrm{~mm}$ were used to aspirate the tissue), 4 to 5 excursions were made on each site of aspiration. Then suction was released and the tissue was expelled into a slide, gently smeared and fixed immediately in $95 \%$ ethyl alcohol. Routine Hematoxylin and eosin stain was performed on the smears. Bilateral open testicular biopsy was performed immediately following the procedure of FNAC of the testes. The anterior scrotal skin was stretched while the testis was lifted and biopsy samples were obtained with small curved scissors through a small scrotal incision without delivering outside the skin or tunica vaginalis to minimize post operative scarring. Hemostasis was obtained with careful use of electrocautery, and the tunica albuginea was closed with fine, absorpable suture as were the layers of the scrotum. The testicular biopsy specimens were immediately placed into freshly prepared Bouins solution (a fixative that does not destroy the testicular architecture) and studied histopathologically both to demonstrate the pattern of sperm production and to rule out underlying testicular pathol- 
ogy such as intratesticular germ cell neoplasia. The results were statistically analysed by using IBM SPSS computer program.

\section{Results}

A total of 67 patients were included in this study. Three men out of the total had unilateral testis. The mean age of the patients studied was 28 years and the mean duration of infertility was 6 years. The clinical characteristics of the patients are shown in (Table 1 ).

Associated urogenital diseases were detected in 31 (46.2\%) patients and varicocele was the most common finding in them (22.3\%) (Table 2).

A total of 131 (FNAC) smears and biopsy specimens obtained from 67 men were studied (3 men had single testis). The following were the morphological diagnosis (Figures 1-7):

1) Normal spermatogenesis $12(17.9 \%)$ revealed all germ cell maturation steps from speramatogonia till mature spermatozoa.

2) Hypospermatogenesis (germ cell hypoplasia) 4 (5.9\%), the smears had less than normal amount of spermatozoa admixed with other cells.

3) Maturation arrest 39 (58.2\%), showed no spermatozoa with presence of immature germ cells, including several primary spermatocytes and spermatids.

4) Sertoli cell only syndrome (germ cell aplasia) 7 (10.4\%), the smears were cellular characterized by complete lack of germ cells and showed only Sertoli cells.

5) No spermatogenesis (complete tubular hyalinization) 5 (7.4\%) (Table 3).

Spermatogenic arrest at the primary spermatocyte or spermatid level presented the most frequently encountered pattern (58.2\%). Most of the patients with non obstructive azoospermia (81.9\%) had small size testis with elevated S.FSH level and those with maturation arrest appeared to have arrested spermatogenesis at the primary spermatocyte stage.

Table 1. The clinical characteristics of the patients with azoospermia.

\begin{tabular}{lc}
\multicolumn{1}{c}{ Clinical characteristics } & No. \\
\hline Mean age (years) & 28 \\
Mean duration of infertility (years) & 6 \\
S.FSH & $52(77.6 \%)$ \\
Normal & $11(16.4 \%)$ \\
Elevated & $4(5.9 \%)$ \\
\hline
\end{tabular}

Table 2. The urogenital diseases found in our patients.

\begin{tabular}{lcc}
\hline \multicolumn{1}{c}{ The disease } & No. of patients & $\%$ \\
\hline Hydrocele & 2 & 2.9 \\
Varicocele & 13 & 19.4 \\
$\quad$ Left side & 2 & 2.9 \\
$\quad$ Bilateral & 6 & 8.9 \\
$\begin{array}{l}\text { Previous epididymo-orchitis } \\
\text { Single testis }\end{array}$ & 3 & 4.4 \\
$\begin{array}{l}\text { Previous groin surgery } \\
\text { (orchiopexy, hernia repair) }\end{array}$ & 5 & 7.4 \\
Total & 31 & 46.2 \\
\hline
\end{tabular}




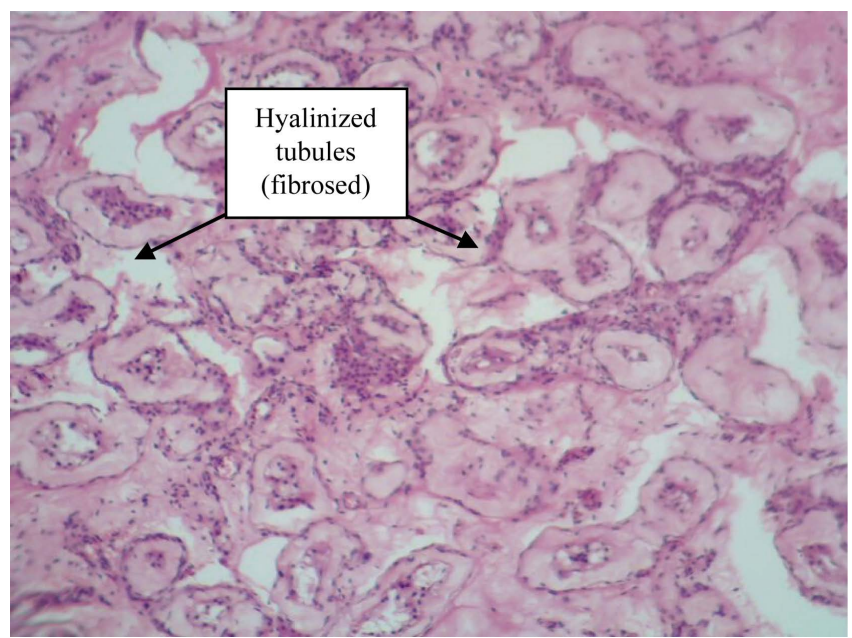

Figure 1. Fibrosis of testes (open testicular biopsy), H\&E, 40×.

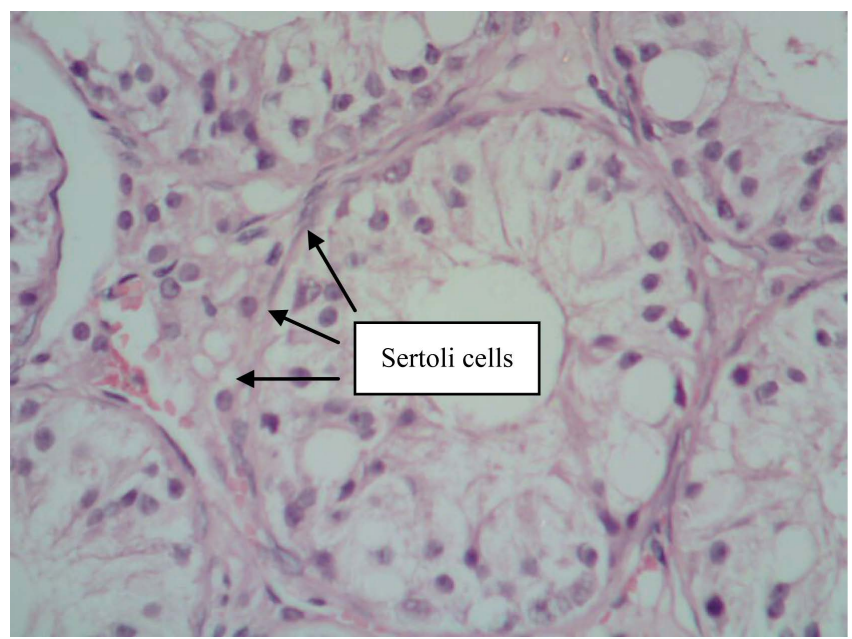

Figure 2. Sertoli Cell Only Syndrome (SCOS) or Germ cell aplasia (open testicular biopsy), H\&E, 100×.

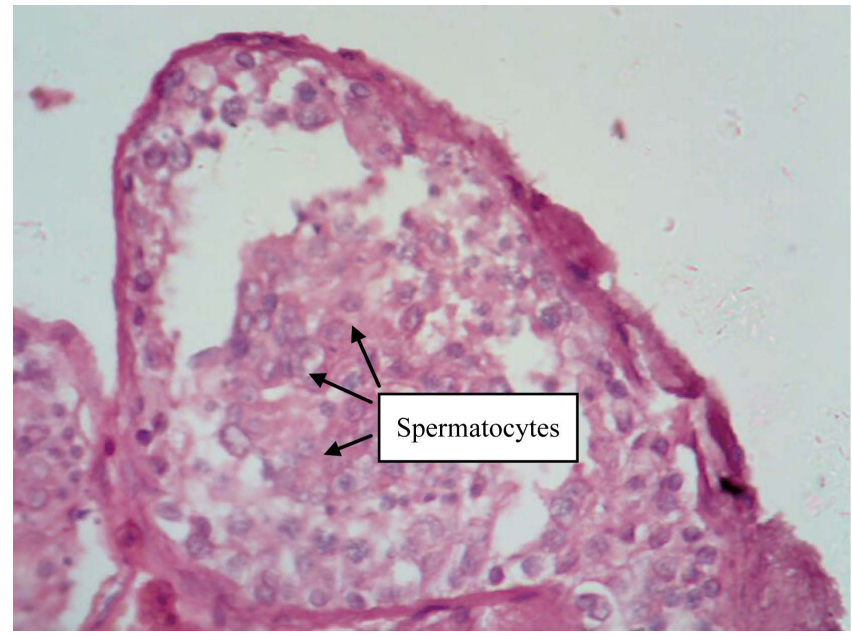

Figure 3. Spermatogenesis arrest (open testicular biopsy), H\&E, $100 \times$. 


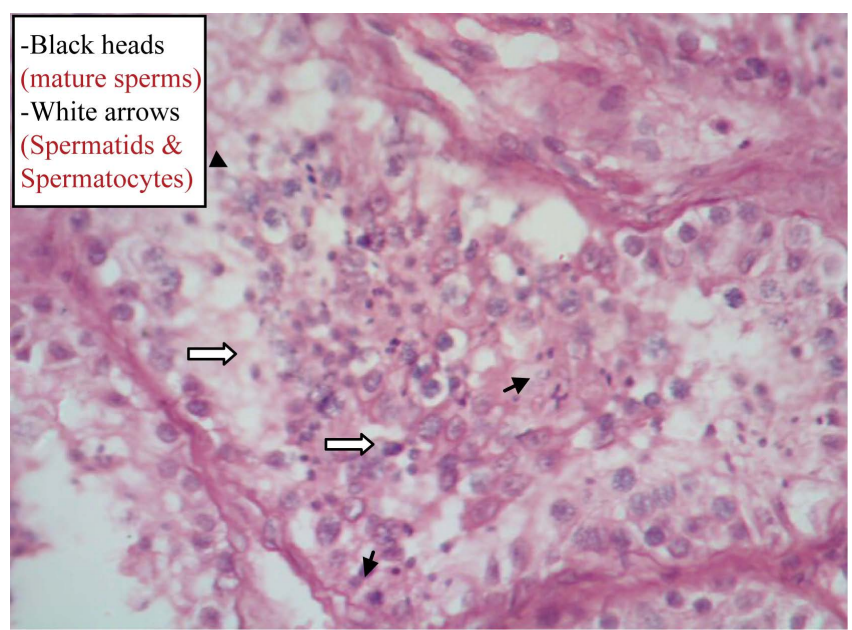

Figure 4. Normal spermatogenesis (open testicular biopsy), H\&E, $100 \times$.

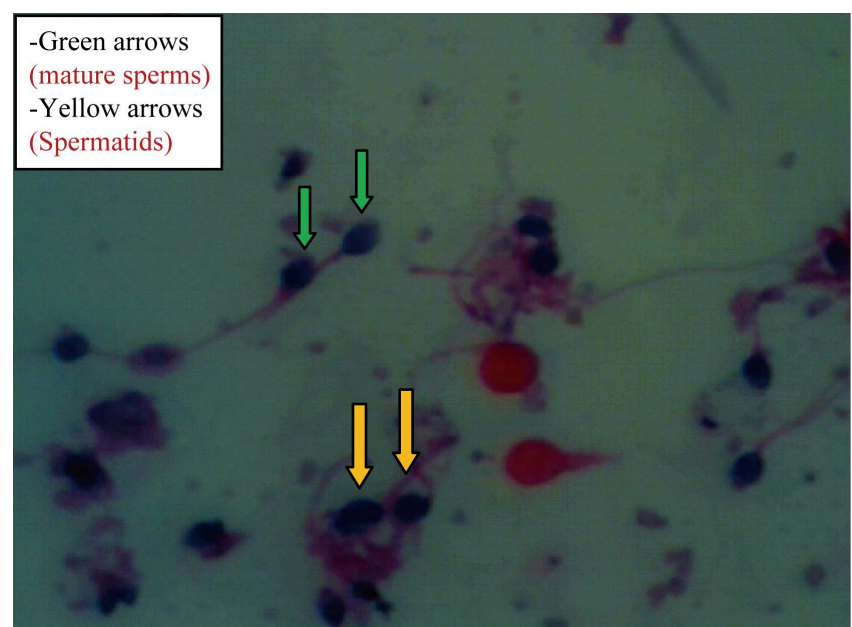

Figure 5. Spermatids \& mature spermatozoa (FNAC), (H\&E, $400 \times)$.

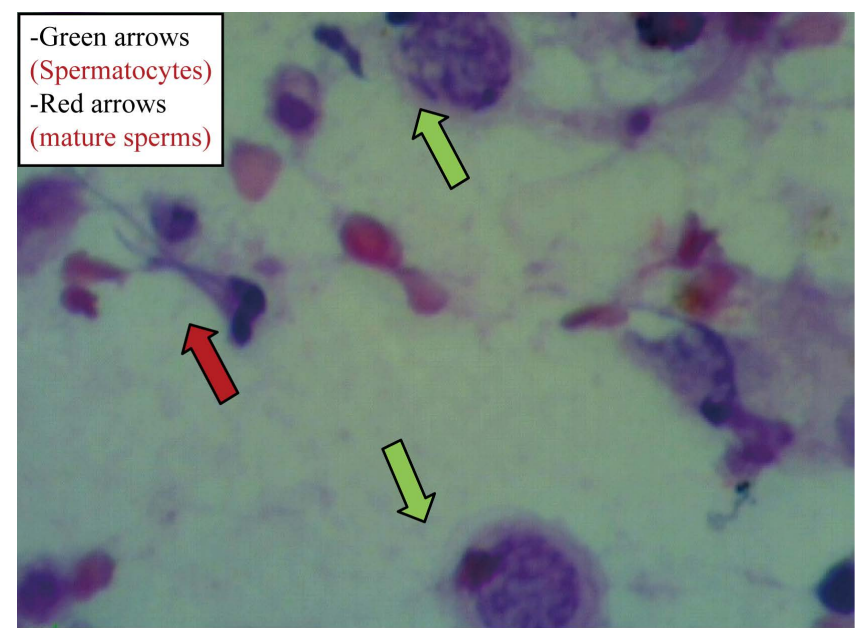

Figure 6. Spermatocytes \& mature spermatozoa (FNAC), (H\&E, $400 \times)$. 


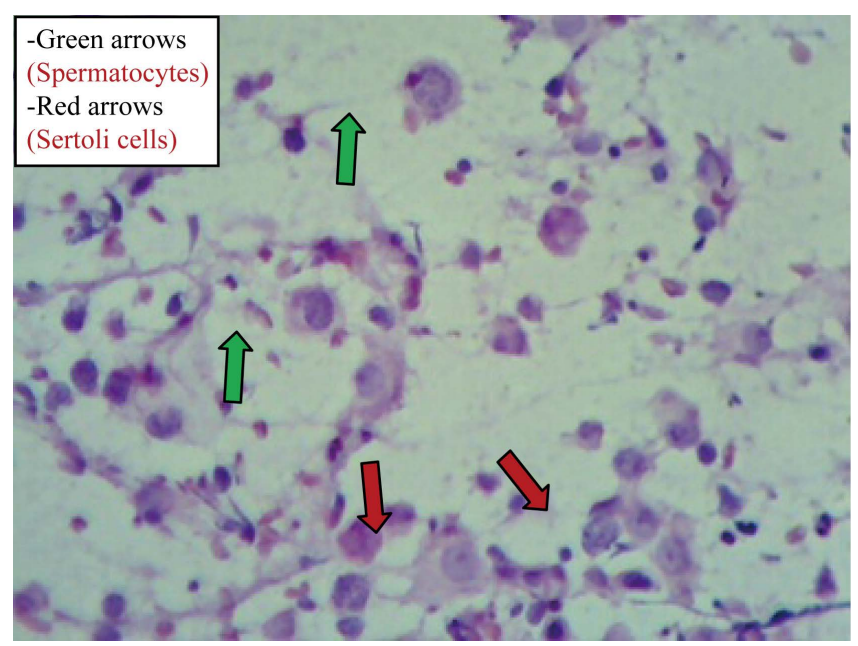

Figure 7. Sertoli cells \& Spermatocytes (FNAC), (H\&E, 400×).

Table 3. The different morphological patterns encountered in the patients.

\begin{tabular}{ccc}
\hline Morphological diagnosis & No. of patients & $\%$ \\
\hline $\begin{array}{c}\text { Normal spermatogenesis } \\
\text { (obstructive azoospermia) } \\
\text { Hypospermatogenesis } \\
\text { (germ cell hypoplasia) }\end{array}$ & 12 & 17.9 \\
Spermatogenic arrest & 4 & 5.9 \\
Sertoli cell only & 39 & 58.2 \\
No spermatogenesis & 7 & 10.4 \\
(complete tubular hyalinization) & 5 & 7.4 \\
Total & 67 & 100 \\
\hline
\end{tabular}

In our study a good correlation was found in 120 (91.6\%) testes between the cytological findings and the results of open biopsy. The correlation was identical in the right and left testis, p value was statistically insignificant ( $p>0.05)$. In 8 cases $(6.1 \%)$ the smears were scanty and insufficient for diagnosis. In 6 out of the 8 cases the corresponding histopathological diagnosis was complete tubular hyalinization. The other 2 showed a histopathology of normal spermatogenesis. Discordant findings were reported in 3 cases (2.3\%) where spermatogenic arrest was recognized in samples obtained by FNA and hypospermatogenesis was demonstrated in samples obtained by open surgical biopsy.

Of the 15 patients with varicocele 8 (53.3\%) of them proved to have normal spermatogenesis in both cytological and histopathological studies. The remaining 7 (46.7\%) patients had abnormalities in their testes. Those included hypospermatogenesis in 4 patients (26.7\%), spermatogenic arrest in $2(13.3 \%)$ and Sertoli cell only syndrome in 1 patient (6.7\%).

\section{Discussion}

Azoospermia is present in about $10 \%-15 \%$ of men evaluated for infertility and represents the final result of different testicular alterations, ranging from normal spermatogenesis with seminal tract obstruction or absence of vas deference (obstructive azoospermia) to different problems of the spermatogenic process including hypospermatogenesis, maturation arrest and complete absence of germ cells or Sertoli cell only syndrome (non obstructiveazoospermia) [9]-[11].

In our study we had found that most of the patients with maturation arrest and elevated S.FSH level had their arrest at the primary spermatocyte stage. This is similar to the results reported by some studies (Amer et al. [12], 
Schulze et al. [13], Seo and Ko [14] and Tsujimura et al. [15]) which studied that S.FSH was elevated in those cases of azoospermia where spermatogenesis was arrested prior to spermatid differentiation. This arrest might be caused by genetics or by secondary influences such as antibiotics, heat or general diseases.

In the present study, obstructive azoospermia (normal testicular volumes, S.FSH with normal histology) represented (17.9\%) of cases. Similar studies recorded by Rashed et al. [16] (24\%), Wong et al. [17] (25\%) and Colgan et al. [18] (20\%). Brannen and Roth [19] reported a higher incidence of obstructive azoospermia (35\%), the same was reported by Al-Rayess et al. [20] (31\%). Thomas j [21] reported an incidence (38\%) for obstructive azoospermia. But on the other side there were studies that reported low incidence, Meinhard et al. [22] reported (5\%) for obstructive azoospermia, also Hddad et al. [23], a study at Jordan reported (11.2\%) for obstructive azospermia, (Table 4). The variation in the incidence reported in these studies could be related to a combination of social habits, environmental conditions and genetics.

The accuracy of FNAC was determined by comparing the FNAC findings with that of the histological findings obtained from an open surgical biopsy, which is taken as the gold standard for the diagnosis. In our study there was a good agreement between the cytological and histological diagnosis. An accuracy of (91.6\%) was achieved. A comparison with other studies is shown in (Table 5) [24].

Table 4. Comparison of obstructive azoospermia percentage with other studies reported in the literature.

\begin{tabular}{cc}
\hline References & \% of obstructive azoospermia \\
\hline Rashed et al. (2008) & 24 \\
Wong et al. (1973) & 25 \\
Colgan et al. (1980) & 20 \\
Brannen and Roth (1979) & 35 \\
Al-Rayess et al. (2000) & 31 \\
Thomas J (1990) & 38 \\
Meinhard et al. (1973) & 5 \\
Haddad et al. (2004) & 11.2 \\
Present study (2015) & 17.9 \\
\hline
\end{tabular}

Table 5. Literaturethat correlates testicular FNA cytology to biopsy histology.

\begin{tabular}{ccc}
\hline Study & No. of patients & \% agreement \\
\hline Persson, 1971 & 42 & 86 \\
Gottschalk-Sabag, 1993 & 47 & 87 \\
Mallidis,1994 & 46 & 94 \\
Craft,1997 & 19 & 84 \\
Odabas, 1997 & 24 & 90 \\
Mahajan, 1999 & 60 & 97 \\
Rammou-Kinia, 1999 & 30 & 87 \\
Mcng, 2000 & 87 & 94 \\
Qubian, 2000 & 34 & 96 \\
Aridogan, 2003 & 40 & 90 \\
Mehrotra, 2007 & 58 & 94 \\
Present study, 2015 & 67 & 91.6 \\
\hline
\end{tabular}


In 3 testicular aspirates diagnosed as hypospermatogenesis by histopatholopgy, fine needle aspiration smears diagnosed them as maturation arrest. In 8 cases in our study, the material aspirated was scanty and insufficient for diagnosis. The corresponding histopathological diagnoses were a majority of 6 cases with complete tubular hyalinization. The other 2 cases showed a histopathology of normal spermatogenesis. These insufficient aspirates were mostly because of the relatively a cellular, fibrosed, atrophied testes.

In diagnosing obstructive azoospermia (normal spermatogenesis) which is considered a correctable posttesticular cause for infertility, the accuracy of FNAC compared to histopathology was $100 \%$.

\section{Conclusions}

1) Testis FNA cytology correlates well with testis biopsy histology in the evaluation of male infertility.

2) Testicular FNA cytology is a simple and minimally invasive procedure that can diagnose accurately testicular histology differentiating obstructive from non obstructive azoospermia and helping in performing sperm extraction for artificial reproductive techniques.

\section{References}

[1] Babolhavaeji, H., Bahar, S.H.M., Anvari, N., et al. (2008) The Study of Detecting Sperm in Testis Biopsy in Men with Severe Oligospermia and Azoospermia by Two Methods of Wet Prep Cytologic and Classic Histopathologic. Indian Journal of Reproductive Medicine, 6, 101-104.

[2] Yildiz-Aktas, I.Z., Monaco, S.E., Khalbuss, W.E., et al. (2011) Testicular Touch Preparation Cytology in the Evaluation of Male Infertility. Cyto Journal, 8, 24.

[3] Geisinger, K.R., Raab, S.S., Stanley, M.W., et al. (2004) Modern Cytopathology. Churchill Livingstone, Philadelphia, 723-724.

[4] Craft, I., Tsirigotis, M., Courtauld, E., et al. (1997) Testicular Needle Aspiration as an Alternative to Biopsy for the Assessment of Spermatogenesis. Human Reproduction, 12, 1483-1487. http://dx.doi.org/10.1093/humrep/12.7.1483

[5] Qublan, H.S., Al-Jader, K.M., Al-Kaisi, N.S., et al. (2002) Fine Needle Aspiration Cytology Compared with Open Biopsy Histology for the Diagnosis of Azoospermia. Journal of Obstetrics and Gynaecology, 22, 527-531. http://dx.doi.org/10.1080/0144361021000003690

[6] Jha, R. and Sayami, G. (2009) Testicular Fine Needle Aspiration in Evaluation of Male Infertility. Journal of Nepal Medical Association, 48, 78-84.

[7] Mehrotra, R. and Chaurasia, D. (2008) Fine Needle Aspiration Cytology of the Testis as the First Line Diagnostic Modality in Azoospermia: A Comparative Study of Cytology and Histology. Cytopathology, 19, 363-368. http://dx.doi.org/10.1111/j.1365-2303.2007.00485.x

[8] Schlegel, P.N. (2009) Non Obstructive Azoospermia: A Revolutionary Surgical Approach and Results. Seminars in Reproductive Medicine, 27, 165-170. http://dx.doi.org/10.1055/s-0029-1202305

[9] Coburn, M. and Wheeler, T.M. (1991) Testicular Biopsy in Male Infertility Evaluation. In: Lipshultz, L.I. and Howards, S.S., Eds., Infertility in Male, 2nd Edition, Mosby Year Book, Philadelphia, 223-253.

[10] Yildiz-Aktas, I.Z., Monaco, S.E., Khalbuss, W.E., et al. (2011) Testicular Touch Preparation Cytology in the Evaluation of Male Infertility. Cyto Journal, 8, 24. http://dx.doi.org/10.4103/1742-6413.91244

[11] European Association of Urology. http://www.Uroweb.Org/professionalresources/guidelines

[12] Amer, M., Haggar, S.E., Moustafa, T., El-Naser, T.A. and Zohdy, W. (1999) Testicular Sperm Extraction: Impact of Testicular Histology on Outcome, Number of Biopsies to be Performed and Optimal Time for Repletion. Human Reproduction, 14, 3030-3034. http://dx.doi.org/10.1093/humrep/14.12.3030

[13] Schulze, W., Thomas, F. and Knuth, U.A. (1999) Testicular Sperm Extraction: Comprehensive Analysis with Simultaneously Performed Histology in 1418 Biopsies from 766 Subfertile Men. Human Reproduction, 14, 82-96. http://dx.doi.org/10.1093/humrep/14.suppl_1.82

[14] Seo, J.T. and Ko, W.J. (2001) Predictive Factors of Successful Testicular Sperm Recovery in Non-Obstructive Azospermia Patients. International Journal of Andrology, 24, 306-310. http://dx.doi.org/10.1046/j.1365-2605.2001.00307.x

[15] Tsujimura, A., Matsumiya, K., Miyagawa, Y., Tohda, A., Miura, H., Nishimura, K., et al. (2002) Conventional Multiple or Microdissection Testicular Sperm Extraction: A Comparative Study. Human Reproduction, 17, $2924-2929$. http://dx.doi.org/10.1093/humrep/17.11.2924

[16] Rashed, M.M., Ragab, N.M., Shalaby, A.R. and Ragab, W.K. (2008) Patterns of Testicular Histopathology in Men with Primary Infertility. The Internet Journal of Urology, 5, Article No. 8836.

[17] Wong, T.W., Straus, F.H. and Warner, N.E. (1973) Testicular Biopsy in the Study of Male Infertility: II. Posttesticular 
Causes of Infertility. Archives of Pathology, 95, 160-164.

[18] Colgan, T.J., Bedard, Y.C., Strawbridge, H.T., Buckspan, M.B. and Klotz, P.H. (1980) Reappraisal of the Value of Testicular Biopsy in the Investigation of Infertility. Fertility and Sterility, 33, 56-60.

[19] Brannen, G.E. and Roth, R.P. (1979) Testicular Abnormalities of the Subfertile Male. Journal of Urology, 122, 575562.

[20] Al-Rayess, M.M. and Al-Rikabi, A.C. (2000) Morphologic Patterns of Male Inferetility in Saudi Patients. A University Hospital experience. Saudi Medical Journal, 21, 625-628.

[21] Thomas, J.O. (1990) Histological Pattern of Testicular Biopsies in Infertile Males in Ibadan, Nigeria. East African Medical Journal, 67, 578-584.

[22] Meinhard, E., McRae, C.U. and Chisholm, G.D. (1973) Testicular Biopsy in Evaluation of Male Infertility. BMJ, 3, 577-581. http://dx.doi.org/10.1136/bmj.3.5880.577

[23] Haddad, F.H., Omari, A.A., Malkawi, O.M., Ajour, W.K., Izat, A., Khasrof, H. and Khawaldeh, A.K. (2004) Patterns of Testicular Cytology in Men with Primary Infertility: Any Change since the Gulf War? Acta Cytologica, 48, 807-812. http://dx.doi.org/10.1159/000326450

[24] “FNA Mapping” (Section FNA Cytology vs Testis Biopsy). 